\title{
TRADISIONALISME DALAM ARSITEKTUR KOLONIAL BELANDA DI KOTA MALANG
}

\author{
Joko Triwinarto Santoso, Noviani Suryasari, Antariksa \\ Jurusan Arsitektur, Fakultas Teknik, Universitas Brawijaya \\ jokotris@ub.ac.id
}

\begin{abstract}
ABSTRAK
Manusia pada dasarnya tidak bisa melepaskan diri dari masa lalu yang melahirkan (tata) nilai dan pemikiran yang diturunkan secara terus-menerus tanpa atau dengan sedikit sekali mengalami perubahan. Paham yang semacam ini disebut sebagai tradisionalisme. Ditengarai, tradisionalisme juga ada dalam arsitektur sebagai produk budaya manusia. Malang sebagai kota yang tumbuh pesat selama masa kolonial Belanda menyimpan sejumlah bangunan yang berasal dari masa itu. Arsitektur bangunan-bangunan ini tentunya merupakan hasil rancangan yang dilandasi berbagai macam paham pemikiran yang salah satunya adalah tradisionalisme.Penelitian yang berupaya mengidentifikasi keberadaan tradisionalisme dalam arsitektur kolonial Belanda ini menggunakan metoda deskriptif(grafis), dengan data yang diperoleh dengan teknik purposive sampling. Hasil yang diperoleh menunjukkan bahwa memang ada pengaruh tradisionalisme dalam arsitektur kolonial Belanda yang terwujud pada dua elemen arsitektural, yaitu atap dan bukaan.
\end{abstract}

Kata kunci: tradisionalisme, arsitektur kolonial Belanda, Malang

\section{ABSTRACT}

People are not able to break away from the past that gave birth to (system) values and thoughts derived continuously without or with very few changes. This kind of understanding is called as traditionalism. Traditionalism is also in the architecture as a product of human culture. Malang as the town grew rapidly during the Dutch colonial period, saved some buildings from that era. Architecture of these buildings is certainly a result of the design which is based on a wide range of ideologies, one of which is tradisionalism. This study that seeks to identify the presence of traditionalism in the Dutch colonial architecture using descriptive methods (graphics), with data obtained by purposive sampling technique. The results obtained indicate that there is influence of traditionalism in the Dutch colonial architecture embodied in the two architectural elements, namely the roof and openings.

Keywords: tradisionalism, Dutch colonial architecture, Malang

\section{Pendahuluan}

\subsection{Manusia dan Tradisi}

Manusia pada dasarnya adalah makhluk multi-dimensional yang dapat ditelaah dari berbagai sudut pandang. Salah satu dimensi yang kita kenal adalah dimensi waktu. Bagi manusia, dimensi waktu biasanya terbagi ke dalam tiga penggal: masa lalu, masa kini dan masa depan. Masa lalu terkait dengan sejarah dan pengalaman hidupnya. Masa kini merupakan penggal dimensi waktu tempat manusia hidup dengan segala kekiniannya. Masa depan adalah penggal waktu saat manusia akan menjalani hidupnya. 
Masa lalu selalu memiliki (tata) nilai yang muncul dan berkembang pada masanya. Jika manusia dihadapkan pada suatu kondisi yang baru tanpa ada persiapan atau pengkondisian, biasanya secara psikologis, manusia akan cenderung untuk kembali kepada nilai-nilai yang sudah dikenalnya yang nyata-nyata berasal dari masa lalu. Nilainilai yang dikenalnya tersebut berkembang dari waktu ke waktu dan diwariskan secara turun-temurun tanpa atau dengan sedikit perubahan. Dengan kata lain, nilai-nilai tersebut mewujud sebagai suatu tradisi.

\subsection{Arsitektur sebagai Perwujudan Tradisi}

Arsitektur merupakan hasil cipta, rasa, dan karsa rekayasa manusia dalam upaya memenuhi kebutuhan hidupnya terkait dengan kebutuhan ruang, wadah atau bangunan. Ada kecenderungan manusia untuk kembali kepada nilai-nilai tradisional (Jencks, 1977) dalam penciptaan arsitektur. Dengan kata lain, ada keinginan manusia untuk menoleh ke belakang, merujuk pada masa lalu.

Kembalinya pandangan manusia pada masa lalu atau kesejarahan dapat disebabkan oleh beberapa faktor:

- Masalah dasar pada arsitektur terbatas jumlahnya dan pada prinsipnya akan tetap sama sepanjang perjalanan sejarah sehingga penyelesaiannya hanyalah penghalusan saja.

- Penyelesaian tersebut, yang telah dilakukan selama ini, sudah merupakan salah satu penyelesaian yang terbaik karena telah diulang secara terus-menerusdan merupakan yang paling dikenal sehingga menjadi hasil yang paling dimengerti.

- Manusia pada dasarnya selalu mempunyai nostalgia masa silam.

Dengan mewujudkan arsitektur yang mentradisi yang dibuat oleh para arsitek untuk beragam pemberi tugas, yang keduanya memiliki beragam latar belakang budaya, maka manusia akan merasa nyaman hidupnya dan tidak berada dalam wadah yang asing dengan dirinya.

\subsection{Malang sebagai Kota Kolonial}

Pada masa kolonial Belanda, awalnya Malang merupakan kota kecil di pedalaman yang secara administratif berada di bawah Karesidenan Pasuruan. Namun, sejak dihapuskannya monopoli yang dimiliki oleh Nederlandsche Handel Maatschappijdan diikuti pemberlakuan liberalisasi di berbagai bidang, atau tepatnya sejak pemberlakuan UU Gula dan UU Agrokultur pada tahun 1870 di Hindia Belanda sebagai hasil tekanan kaum liberal di Belanda, maka Malang tumbuh menjadi kota nomer dua setelah Surabaya di Jawa Timur. Malang menjadi kota penunjang bagi Surabaya dalam hal fungsi-fungsi yang tidak (tepat) terakomodasi di kota pertama. Selanjutnya, Malang berkembang secara lebih cepat setelah jalur kereta api Surabaya-Pasuruan-Malang dibuka pada tahun 1878.

Dengan ditetapkannya Undang-undang Desentralisasi (Decentralisatie Wet) di Hindia Belanda pada tahun 1903, maka diperkenalkan suatu administrasi baru yang mengakhiri dominasi administrasi pusat di Batavia. Hal ini membuka jalan pemberlakuan Ordonasi Dewan Lokal (Locale Radenordonantie) yang menetapkan peraturan bagi pembentukan pemerintah lokal atau kotamadya (gemeente).Malang ditetapkan sebagai gemeente pada tanggal 1 April 1914. Dengan penetapan tersebut, pemerintah lokal mempunyai kewenangan untuk mengatur kotanya. Salah satu yang dilakukan adalah dengan meminta Thomas Karsten untuk menyusun rencana pengembangan kota. Rencana ini diwujudkan secara bertahap (satu sampai dengan 
delapan) sejak tahun 1917 hingga tahun 1929 dengan masing-masing area pengembangan (bouwplan) memiliki jenis peruntukkan tertentu.

Dari paparan di atas, penelitian ini ingin menjawab pertanyaan: apakah ada pengaruh tradisionalisme dalam arsitektur kolonial Belanda di Kota Malang? Selanjutnya, jika ada, jenis atau pengaruh tradisionalisme manakah yang terwujud pada elemen-elemen arsitekturalnya? Jika tidak ada, mengapa hal tersebut bisa terjadi?

\section{Bahan dan Metode}

\subsection{Tradisionalisme dalam Arsitektur}

Barbieri dan Van Duin (2003) membagi perkembangan arsitektur di Belanda pada paruh pertama abad XX menjadi empat kelompok pemikiran besar, yaitu: tradisionalisme, rasionalisme, ekspresionisme dan fungsionalisme. Istilah "tradisionalisme", yang berasal dari kata "tradisi", didefinisikan oleh Van Duin (2003: 15) sebagai suatu paham atau pemikiran penegakan atau pemeliharaan tradisi, khususnya pemikiran yang menolak suatu perubahan. Dalam khazanah arsitektur di Belanda, pemikiran ini sudah muncul sejak abad sebelumnya.

Rahaju B.U.K (2010) menyatakan bahwa arsitektur tradisional sangat menekankan keterkaitan antara arsitektur dengan tradisi yang diturunkan dari generasi ke generasi. Tetapi dia juga menekankan bahwa tradisi adalah produk budaya yang selalu akan berubah. Menurutnya, pemahaman yang saat ini berkembang adalah anggapan bahwa arsitektur tradisional adalah bagian dari arsitektur vernakular.

Vletter (2007), dan juga Akihary (1990), menjelaskan diskursus, yang terjadi pada awal dasa warsa 1920an, tentang tradisi dan modernitas dalam arsitektur yang berkembang di Indonesia pada saat itu. Vletter menjelaskan bahwa arsitek Henri Maclaine Pont yang didukung oleh Thomas Karsten lebih memilih tradisi arsitektural yang berkembang di masyarakat untuk diterapkan pada arsitektur kontemporer saat itu. Sebaliknya, Charles Wolff Schoemaker berpendapat bahwa arsitektur yang pantas dikembangkan di Indonesia adalah arsitektur modern Eropa yang sudah disesuaikan dengan iklim tropis setempat. Kedua pandangan yang bertolak belakang ini pada akhirnya mampu menjadi dasar pengelompokan perwujudan arsitektur kolonial Belanda yang berkembang pada masanya. Perbedaan sudut pandang kedua penulis tersebut terletak pada acuan tradisionalisme. Jika Akihary hanya mengartikan tradisional sebagai sifat atau karakter bangunan yang merujuk ke arsitektur di Belanda atau Eropa pada umumnya, maka bagi Vletter istilah itu mengacu pada arsitektur masa lalu, tanpa membedakan asal arsitektur, sebagai lawan dari modern.

Dalam artikelnya, Wuismann (2007: 29-31) mengidentifikasi berbagai macam pengaruh yang dapat membentuk arsitektur di Indonesia. Pengaruh tersebut mencakup:

- Pengaruh arsitektur Hindu/Budha

- Pengaruh arsitektur Tionghoa

- Pengaruh arsitektur muslim

- Pengaruh arsitektur Eropa

Jika ditambah dengan arsitektur vernakular di Indonesia, maka kelima jenis tradisi arsitektural tersebut bisa dipakai sumber pengaruh ada-tidaknya tradisionalisme pada arsitektur kolonial Belanda di wilayah studi.

\subsection{Arsitektur Kolonial Belanda di Indonesia pada Umumnya dan Malang pada Khususnya}


Studi tentang arsitektur kolonial di Indonesia, baik yang merupakan bagian dari sejarah arsitektur di Indonesia secara umum maupun yang khusus berdiri sendiri, sudah pernah dilakukan oleh beberapa penulis.Sudrajat (1991) melakukan studi yang termasuk ke dalam kategori pertama. Ia mencoba menelusuri perkembangan (sejarah) arsitektur di Indonesia dengan mulai dari tinjauan sejarah arsitektur sebagai warisan tradisi pemikiran arkeologis dan antropologis Belanda hingga warisan pemikiran sosiologis dan perencanaan kota Belanda. Bahasan tentang arsitektur kolonial Belanda terfokus pada pencarian identitas arsitektur dengan melalui penerapan langgam (style) arsitektur Indo-Eropa.Temuannya menunjukkan bahwa langgam arsitektur Indo-Eropa berhenti terbatas pada tataran konsep atau ide, tidak terimplementasi pada wujud fisik arsitektural.

Masuk ke dalam kategori kedua, Jessup (1988) memaparkan pengaruh arsitektur Belanda di Indonesia pada periode 1900-1942. Dalam analisisnya, ia memfokuskan studinya pada karya-karya Henri Maclaine Pont dan Thomas Karsten dengan latar (setting) Eklektisisme dan Internasionalisme dalam arsitektur. Studi yang lain dilakukan oleh Sumalyo (1993). Ia lebih memberi perhatian kepada tujuh arsitek dan biro arsitektur yang berpraktek di Indonesia. Temuannya menunjukkan bahwa dari beberapa arsitek dan biro konsultan tersebut sebagian dari mereka mencoba memasukkan unsur lokal sebagai bagian dari tradisi ke dalam karta-karya mereka, sedangkan sisanya tetap lebih berkiblat pada arsitektur modern yang sama sekali tidak memasukkan pertimbangan tradisi lokal, kecuali sebatas adaptasi terhadap iklim setempat.

Selanjutnya, Soekiman (2000 dan 2007) meneliti tentang pengaruh kebudayaan Belanda pada kebudayaan di Jawa, termasuk arsitektur, yang akhirnya melahirkan apa yang disebut sebagai kebudayaan Indis. Kebudayaan ini adalah suatu kebudayaan (di) Indonesia, khususnya arsitektur di Indonesia, yang mendapat pengaruh dari kebudayaan Eropa, khususnya Belanda. Dengan kata lain, arsitektur yang terwujud merupakan paduan antara arsitektur barat (Belanda) dengan arsitektur lokal yang bersifat tradisional.

Di samping kepustakaan yang diulas di atas, masih ada beberapa pustaka tentang arsitektur kolonial Belanda yang masing-masing hanya fokus pada satu arsitek seperti yang ditulis oleh Akihary (1996), van Leerdam (1998), Segaaar-Höweler (1998), Segaaar-Höweler dan Boersma (2000), Dikken (2002), de Vries dan Segaaar-Höweler (2009), van Dullemen (2010), Santoso (2010).

Pustaka yang khusus mengulas tentang Malang dengan sejarah dan arsitekturnya, bisa ditemukan pada karya Handinoto dan Soehargo (1996) dan van Schaik (1996). Bahasan arsitektural dalam pustaka pertama lebih rinci dibanding dengan pustaka kedua.

Dari semua paparan di atas dapat ditarik kesimpulan awal bahwa:

- Patut diduga bahwa keberadaan arsitektur kolonial Belanda di Malang Raya mengandung tradisionalisme, yang diartikan sebagai paham pemikiran untuk menghadirkan elemen-elemen arsitektural yang sudah mentradisi.

- Tradisionalisme yang mewujud tersebut bisa dipengaruhi dari beberapa sumber arsitektur pemberi pengaruh, yaitu:

- Arsitektur lokal vernakular

- Arsitektur Hindu/Budha

- Arsitektur peranakan Tionghoa

- Arsitektur muslim

- Arsitektur vernakular Belanda atau Eropa pada umumnya.

\subsection{Metoda Penelitian}


Penelitian ini mengambil area studi yang mencakup area-area yang dahulunya merupakan area bouwplan I sampai dengan VIII menurut rencana pengembangan Kota Malang yang dibuat oleh Thomas Karsten. Untuk lebih jelasnya, area studi dapat dilihat pada gambar 1.

Populasi dalam penelitian ini adalah seluruh bangunan berkarakter tradisional yang berada di bouwplan I sampai dengan VIII Kota Malang. Pemilihan sampel yang menjadi unit amatan dilakukan menggunakan metoda purposive sampling, yaitu teknik pengambilan sampel dengan pertimbangan tertentu (Sugiyono, 2006: 95). Teknik ini diterapkan jika populasi penelitian bersifat tidak homogen (Muhadjir, 1989: 39).

Kriteria bangunan yang akan dijadikan sampel adalah sebagai berikut:

- bangunan didirikan pada masa pelaksanaan bouwplan yang bersangkutan;

- bangunan terpilih masih dalam kondisi asli, atau jika sudah berubah, perubahan tersebut tidak terlalu signifikan sehingga karakter visual yang asli tetap terjaga;

- bangunan terpilih memiliki sedikitnya satu elemen pada atap dan/atau bukaan pada fasade yang menunjukkan ciri tradisionalisme, baik yang berasal dari lokal vernakular, Hindu/Budha, Tionghoa, muslim ataupun Eropa.

Dari pengamatan awal di lapangan, terpilih 96 sampel yang tersebar ke dalam delapan bouwplan. Rincian sebaran lokasi sampel tersaji ke dalam tabel 1.

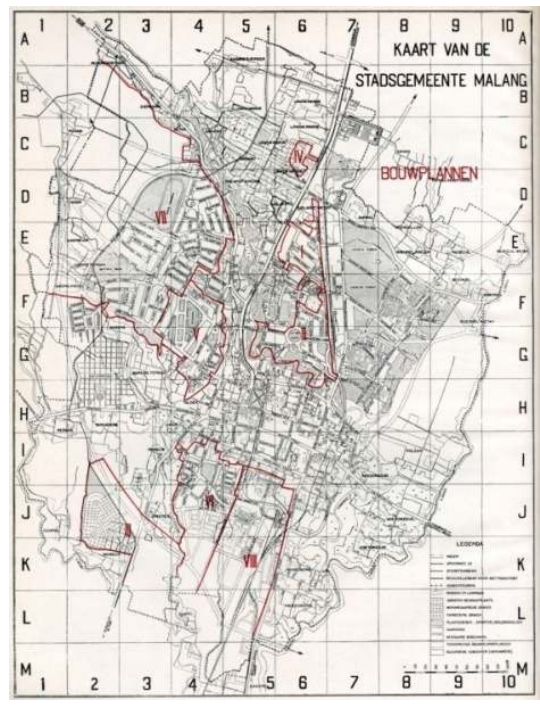

Gambar 1. Rencana Pengembangan Kota Malang Menurut T. Karsten dan Area Studi Penelitian

(Sumber: Liempt, 1939)

Tabel 1. Sebaran Lokasi Sampel

\begin{tabular}{|c|c|}
\hline Bouwplan & Sampel \\
\hline I & 13 \\
\hline II & 7 \\
\hline III & 1 \\
\hline IV & 16 \\
\hline V & 16 \\
\hline VI & 12 \\
\hline VII & 26 \\
\hline VIII & 5 \\
\hline Jumlah & 96 \\
\hline
\end{tabular}


Sampel terpilih direkam secara visual dengan pemotretan dari titik pandang yang mampu memberi gambaran yang cukup signifikan sampel tersebut. Hasilnya disunting seperlunya (cropping, pengaturan kecerahan, dll) dan kemudian dimasukkan ke dalam matriks yang berisi data fungsi awal, fungsi sekarang, alamat, bouwplan, dan foto sampel.Di tiap matriks diidentifikasi keberadaan terapan tradisionalisme pada fisik bangunan dengan variabel atap dan bukaan pada fasade.Selanjutnya, diidentifikasi asal pengaruh elemen tradisional dan diakhiri dengan mengelompokkan (elemen) tradisionalisme atas dasar asal pengaruhnya.

\section{Hasil dan Pembahasan}

\subsection{Bouwplan I}

Pada bouwplan I, variasi unsur tradisional cukup beragam, meski didominasi pengaruh tradisionalisme dari Eropa. Hal ini bisa dimaklumi karena target konsumennya adalah masyarakat Eropa yang tentu saja berpenghasilan tinggi.

Dalam hal atap untuk bangunan satu lantai dijumpai fenomena sebagai berikut:

- Untuk bangunan satu lantai, dominasi pemakaian gable (dinding depan bangunan) yang mengakhiri atap pelana dijumpai pada sampel di Jl. Dr. Cipto 10 dan 12, Jl. Dr. Wahidin 80, Jl. Cokroaminoto 20, Jl. Kartini 1, 14 dan 28, Jl. Dr. Sutomo 25, serta di Jl. Diponegoro 4.

- Bagi sampel yang tidak memakai gable, dijumpai atap sekunder dengan raut dasar segi banyak dengan atap limas segi banyak juga yang ditempel (aditif) di bagian depan pada atap utama berbentuk limas. Fenomena ini dijumpai pada bangunan di Jl. Dr. Wahidin 46 dan 48, Jl. Dr. Sutomo 2, Jl. Diponegoro 4.

- Bentuk atap cukup unik dijumpai di Jl. Dr. Sutomo 2. Di sini penyelesaiannya menyerupai bentuk yang lazim dijumpai pada arsitektur abad pertengahan Eropa, khususnya fungsi pertahanan (fortifikasi), yaitu parapet (dinding/penghalang rendah pada tepi atap).

Sampel yang berlantai dua hanya satu, yaitu sekolah di Jl. Dr. Sutomo 35. Di sini, bangunan beratap limas yang dikombinasikan dengan atap pelana.

Untuk raut bukaan dijumpai fenomena sebagai berikut:

- Mayoritas memakai raut persegi.

- Bukaan dengan bagian atas beraut lengkung segmental (segmental arch) dijumpai pada bangunan di Jl. Kartini 1, Jl. Dr. Sutomo 2 dan Jl. Diponegoro 4.

- Bukaan dengan bagian atas beraut beraut lengkung meruncing di puncak (pointed arch) ditemukan pada bangunan di Jl. Dr. Cipto 12. Elemen ini mengingatkan pada elemen serupa pada masa (neo-) Gotik.

- Bukaan dengan bagian atas beraut segitiga sama kaki dijumpai pada bangunan di Jl. Dr. Wahidin 60 dan Jl. Kartini 14. Bukaan ini diterapkan baik pada gerbang masuk (Jl. Dr. Wahidin 60) dan jendela (Jl. Kartini 14).

\subsection{Bouwplan II}

Sebagai pusat pemerintahan baru bagi Kota Malang, bouwplan II didominasi oleh keberadaan gedung balaikota dan sekolah. Keduanya dirancang sebagai bangunan dua lantai. Balaikota beratap limas segi empat susun tiga di bagian tengah dan diapit oleh atap limas. Sementara untuk komplek bangunan sekolah, ditandai dengan atap pelana dengan sudut besar atau curam (hampir $60^{\circ}$ ) untuk menaungi bangunan dua lantai. Ada perpanjangan nok atap dengan ornamen yang mencuat keluar sehingga menyerupai ornamen serupa yang dijumpai di beberapa atap bangunan tradisional di Nusantara. 
Sampel yang lain didominasi bentuk atap limas yang sudah mengalami proses adisi. Atap setengah limas dijumpai pada rumah tinggal Jl. Gajah Mada 3. Atap sekunder yang ditempelkan pada atap primer biasanya diselesaikan dengan pemakaian gable. Ini bisa dilihat pada bangunan di Jl. Gajah Mada 5 dan 6 serta Jl. Tumapel 6. Rumah tinggal di Jl. Suropati 10, yang didirikan pada tahun 1926, memiliki gable yang menutupi (hampir) seluruh atap bangunan. Bagian ini distilistika dengan ornamen geometris.

Raut bukaan tetap didominasi persegi. Rumah tinggal yang berada di Jl. Gajah Mada 3 mempunyai bukaan dengan bagian atas berraut lengkung semi sirkular (setengah lingkaran) di bagian gerbang masuk maupun di jendelanya.

\subsection{Bouwplan III}

Pada sampel dibouwplan ini, yaitu gerbang Makam Sukun, desain bangunannya menunjukkan pengaruh arsitektur Eropa. Bentuk vertikal yang sangat menonjol dipadu dengan bentuk atap mansard di sebelah kiri dan kanannya menghasilkan bentuk massa yang sangat atraktif. Unit vertikal diolah membentuk segi delapan di bagian puncak.

Fasade diperkaya dengan bukaan berraut segi enam dengan satu titik puncak yang berfungsi sebagai gerbang masuk. Di sebelah atasnya terdapat 3 unit bukaan berjajar dan satu buah bukaan berraut lingkaran menyerupai jendela roda pada arsitektur (neo-) Gotik.

\subsection{Bouwplan IV}

Dari ke-16 sampel terpilih di bouwplan IV menunjukkan bahwa semuanya menunjukkan tradisionalisme yang berakar dari arsitektur lokal vernakular. Temuan ini didasari oleh pemakaian bentuk atap limas, baik yang atap limas murni atau atap limas pengembangan. Atap limas pengembangan dihasilkan dari konfigurasi atap yang ditambahkan (aditif) sehingga ada atap primer dan sekunder.

Bentuk atap limas cukup tepat dikaitkan dengan target konsumen pada saat bouwplan dibangun, yaitu golongan masyarakat berpenghasilan bawah sampai dengan menengah. Dengan kemiringan bidang atap mulai dari $35^{\circ}$ hingga $45^{\circ}$ maka:

- biaya konstruksi atap cukup murah;

- persyaratan kemiringan minimal untuk bahan penutup atap genting bisa tercapai; dan

- ruang bawah atap sebagai buffer udara cukup tersedia sehingga suhu ruang di dalam rumah tetap terasa nyaman jika dikaitkan dengan aspek iklim.

Empat dari 16 sampel menunjukkan olahan atap yang menarik. Lokasi keempat sampel tersebut berada di Jl. Sarangan 6, Jl. Sarangan 12, Jl. Sarangan Atas 11, dan Jl. Mawar II/9. Keempatnya menggunakan olahan atap dengan memperpanjang nok atau bubungan atap sehingga tercipta tonjolan atap ke arah depan. Olahan seperti ini mengingatkan pada bentuk-bentuk atap rumah tradisional di Nusantara.

Semua bukaan yang terdapat di seluruh sampel memakai raut persegi. Pilihan terhadap raut ini paling tepat terkait dengan segmen masyarakat yang dituju, yaitu golongan kecil sampai menengah.

\subsection{Bouwplan $V$}

Semua sampel di bouwplan ini menggunakan atap limas, kecuali pada bangunan di Jl. Welirang 24. Atap limas sebagai atap primer dikombinasikan dengan atap sekunder yang berbentuk limas juga atau atap pelana. Atap sekunder limas segi empat terdapat di sampel Jl. Tangkuban Prahu 83, sedangkan atap sekunder limas segi banyak terdapat di 
Jl. Welirang 26. Sisa sampel dengan atap sekunder yang lain, yang merupakan mayoritas, memiliki atap sekunder pelana.

Atap sekunder pelana seluruhnya dipadu dengan penggunaan gable, baik yang terbuat dari bata maupun yang tersusun dari kombinasi bata dan (papan) kayu. Gable bata dijumpai di sampel Jl. Bromo 2, Jl. Bromo 5, Jl. Bromo 17 serta Jl. Tengger 10 dan 12. Sedangkan gable kombinasi bata dan (papan) kayu dapat ditemui di sampel Jl. Sumbing 28, Jl. Welirang 24, Jl. Bromo 17 (utara), Jl. Bromo 24, Jl. Semeru 38 dan Jl. Arjuno 24.

Fenomena menarik yang tidak terdapat di bouwplan-bouwplansebelumnya adalah pemakaian atap pelana terpancung (atap setengah limasan). Atap ini djumpai pada bangunan di Jl. Tengger 10 dan 12. Bangunan ini merupakan rumah kopel atau gandeng dua. Keberadaan atap pelana terpancung dikombinasi dengan pemakaian gable bata.

Bangunan di Jl. Bromo 2 memiliki menara beratap limas segi delapan. Keberadaan elemen ini tidak bisa dilepaskan dari fungsinya sebagai gereja dan posisinya yang berada di sudut jalan. Oleh sebab itu, keberadaan menara sekaligus juga merupakan vocal point bangunan ini. Atap menara distilistika dengan penambahan elemen-elemen vertikal pada bubungannya sehingga terbentuk 'sirip-sirip' atap.

Atap mansard ditemui pada bangunan di Jl. Bromo 5 dan Jl. Bromo 17 (selatan). Pada bangunan di Jl. Merapi 1 ditemukan kombinasi antara atap limas yang diperpanjang bubungan atapnya dengan atap lonceng (bell-cast). Atap lonceng merupakan 'kebalikan' dari atap mansard. Jika atap mansard didefinisikan sebagai atap yang memiliki dua kemiringan bidang atap dengan bidang atap bawah mempunyai kemiringan lebih besar, maka pada atap lonceng kemiringan bidang atap bawah lebih kecil atau landai dibanding bidang atap atas. Atap ini disebut demikian karena raut potongan melintang menyerupai raut lonceng atau bel.

Perpanjangan bubungan atap juga terlihat pada bangunan di Jl. Sumbing 6 .

Bukaan pada sampel didominasi bukaan berraut persegi. Namun demikian, dijumpai dormer pada sampel di Jl. Bromo 17 (selatan).

\subsection{Bouwplan VI}

Mayoritas sampel beratap (primer) limas, kecuali bangunan di Jl. Sulawesi 34 yang beratap pelana dengan kemiringan curam dan bangunan di Jl. Sumba 7 yang beratap lonceng. Fenomena menarik terdapat pada sampel di Jl. Sumba 6. Bangunan ini memiliki parapet yang mengelilingi atap sekunder yang beraut dasar segi delapan. Desain parapet serupa dengan elemen sejenis pada arsitektur Eropa abad pertengahan yang sering dipakai pada bangunan fortifikasi (pertahanan). Selain itu, terdapat juga sampel yang memiliki dormer dan cerobong asap, yaitu bangunan di Jl. Bengkalis 4. Satu sampel, yaitu bangunan di Jl. Sumba 8, mempunyai atap sekunder dengan perpanjangan bubungan atap. Pemakaian gable dijumpai pada sampel Jl. Kalimantan 7 dan Jl. Sulawesi 34.

Seluruh sampel di bouwplan ini memiliki bukaan berraut persegi kecuali bangunan di Jl. Belitung 10 yang juga mempunyai bukaan berraut lingkaran pada jendela.

\subsection{Bouwplan VII}

Di bouwplan ini ada beberapa desain atap yang digunakan:

- Atap limas, baik limas tunggal, limas aditif atau limas sekunder, ditemui di sebagian besar sampel, kecuali sampel Jl. Ijen 66 dan Jl. Lawu 19.

- Atap pelana, baik sebagai atap primer atau atap sekunder, digunakan pada sampel Jl. Ijen 2, Jl. Ijen 3, Jl. Ijen 49, Jl. Ijen 57, Jl. Ijen 66, Jl. Ijen 78, Jl. Ijen 94, Jl. Guntur 2, Jl. Argopuro 13, Jl. Lawu 6, Jl. Lawu 12, Jl. Rinjani 14, Jl. Tanggamus 7 dan Jl. Pandan 15. Tiga sampel di Jl. Ijen 66, Jl. Guntur 2, Jl. Lawu 12 dan Jl. Rinjani 14 memakai atap 
dengan kemiringan yang besar $\left(>45^{\circ}\right)$. Bahkan untuk sampel Jl. Ijen 2 sudut kemiringan atapnya hampir mendekati $90^{\circ}$.

- Atap lonceng dipakai di bangunan Jl. Malabar 11A, Jl. Lamongan 8, Jl. Argopuro 13, Jl. Lawu 8, Jl. Lawu 6 dan Jl. Rinjani 4. Dua yang terakhir olahan atapnya dilengkapi dengan perpanjangan bubungan atap.

- Atap dengan perpanjangan bubungan atap dipakai di bangunan di Jl. Sindoro 7, Jl. Welirang 49, Jl. Lawu 6, Jl. Lawu 12 dan Jl. Rinjani 14 adalah sekian dari bangunan yang memakai olahan atap dengan perpanjangan bubungan atap. Kemungkinan besar, desain tipe vila dan keberadaan di daerah tropis menjadi alasan pemakaian desain semacam ini.

- Atap limas segi banyak (biasanya segi delapan) dipakai di bangunan Jl. Raung 15 dan Jl. Welirang 49.

- Atap dengan gable dijumpai di bangunan Jl. Lawu 12, Jl. Rinjani 14, Jl. Tanggamus 7 dan Jl. Pandan 15.

- Atap mansard dipakai di bangunan Jl. Lawu 19. Di sini atap mansard dipadu dengan atap lonceng sehingga atap tersebut mempunyai tiga kemiringan bidang atap.

- Atap kerucut ditemui pada atap tersier sampel Jl. Guntur 2

Pemakaian menara kembar dijumpai pada sampel di Jl. Guntur 2. Fenomena ini bisa dipahami karena fungsi bangunannya adalah gereja sehingga membutuhkan wadah lonceng.

Sebagian besar bukaan pada fasade menggunakan raut persegi. Pada sampel Jl. Pandan 15 ditemukan pemakaian raut semi-sirkular untuk bukaan pintu dan jendela utama. Jendela roda yang dilengkapi dengan enam bukaan kecil mengelilinginya dipakai pada fasade Gereja Jl. Guntur 2. Kedua jenis bukaan tersebut masih ditambah dengan tiga bukaan besar sebagai gerbang masuk utama dengan bidang atas berraut semisirkular dan tujuh raut sejenis yang lebih kecil di atasnya.

\subsection{Bouwplan VIII}

Dari kelima sampel, bisa diidentifikasi tiga bangunan beratap primer berbentuk limas, yaitu bangunan di Jl. R.E. Martadinata 78, Jl. R.E. Martadinata 84 dan Jl. Sonokeling 12. Atap sampel yang terakhir dilengkapi dengan perpanjangan bubungan atap. Atap primer berbentuk pelana dipakai di bangunan Jl. Prof. M. Yamin 5 dan Jl. Prof. M. Yamin IV/2. Gable dijumpai pada sampel Jl. Jl. R.E. Martadinata 78, Jl. R.E.Martadinata 84 dan Jl. Prof. M. Yamin 5. Keberadaan menara dijumpai pada sampel Jl. R.E.Martadinata 84 dan Jl. Prof. M. Yamin 5. Pada sampel yang disebut pertama menara diatapi dengan atap mansard, sedangkan pada sampel berikutnya beratap limas sudut curam dan berfungsi sebagai wadah lonceng. Untuk bangunan di Jl. Prof. M. Yamin IV/2 dijumpai atap sekunder berbentuk lonceng. Atap ini lebih menyiratkan kesan sebagai bangunan berarsitektur Tionghoa. Dugaan ini diperkuat dengan adanya ornamen geometris yang ada di dinding depan fasade bangunan.

Bukaan didominasi bukaan berraut persegi. Pada sampel Jl. R.E.Martadinata 84 ditemui bukaan yang bagian atas berraut lengkung semi-sirkular dan lengkung segmental.

\subsection{Pembahasan}

\subsubsection{Atap}

Secara umum, sampel memiliki memiliki dua jenis atap ditinjau dari unsur pembentuknya, yaitu atap tunggal dan atap majemuk. Atap tunggal merupakan atap 
yang dibentuk oleh satu jenis atap murni (pelana, limas, dll.), sedangkan atap majemuk/aditif merupakan gabungan dari dua atau lebih jenis atap. Atap majemuk tersusun dari atap primer atau utama dan sekunder atau penunjang. Di tiap jenis atap tersebut (tunggal dan majemuk) dipilah-pilah lagi menurut bentuk dasar dan keberadaan elemen-elemen lainnya. Secara lebih ringkas, tipe-tipe atap yang dipakai disajikan dalam matriks berikut ini.

Tabel 2. Tipe Atap

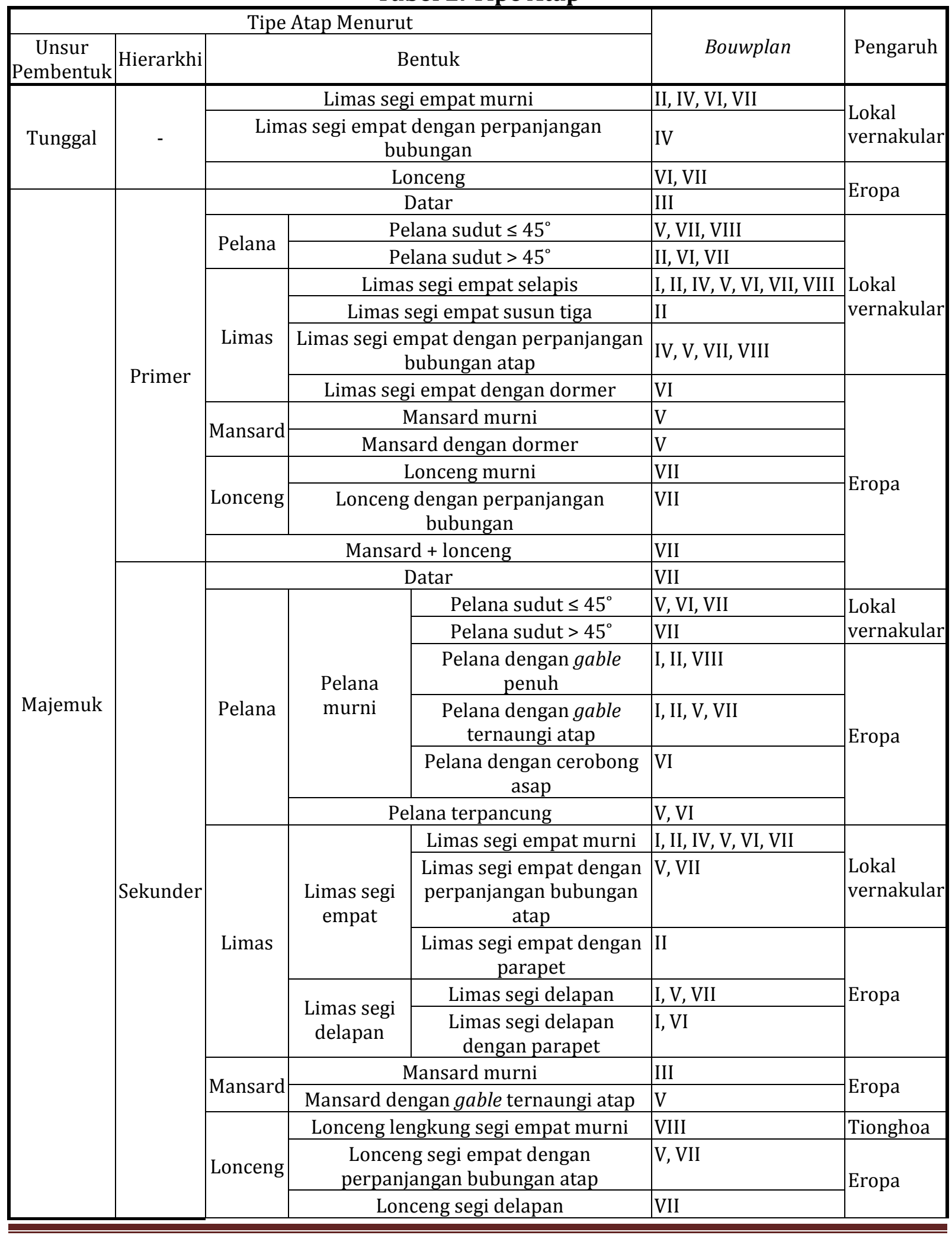




\begin{tabular}{|c|c|c|c|c|c|c|}
\hline \multicolumn{5}{|c|}{ Tipe Atap Menurut } & \multirow[b]{2}{*}{ Bouwplan } & \multirow{7}{*}{ Pengaruh } \\
\hline $\begin{array}{c}\text { Unsur } \\
\text { Pembentuk } \\
\end{array}$ & Hierarkhi & \multicolumn{3}{|c|}{ Bentuk } & & \\
\hline & & \multicolumn{3}{|c|}{ Mansard + lonceng } & VII & \\
\hline & & \multicolumn{3}{|c|}{ Kerucut } & VII & \\
\hline & & \multirow{3}{*}{ Menara } & \multirow{2}{*}{ Limas } & Limas segi empat & VII, VIII & \\
\hline & & & & Limas segi delapan & $\mathrm{V}$ & \\
\hline & & & \multicolumn{2}{|r|}{ Mansard } & VIII & \\
\hline
\end{tabular}

Dari tabel di atas terlihat bahwa:

- Tipe atap limas tunggal segi empat banyak dijumpai di bouwplan II, IV, VI, VII.

- Tipe atap lonceng tunggal ditemui di bouwplan VI dan VII.

- Untuk atap primer, dominasi atap limas segi empat murni terlihat di sebagian besar bouwplan.

- Tipe atap primer mencakup atap datar, pelana, limas, mansard, lonceng dan kombinasi mansard dan lonceng.

- Tipe atap sekunder meliputi atap datar, pelana, limas, mansard, lonceng, kombinasi mansard dan lonceng, kerucut serta menara.

- Variasi tipe atap banyak ditemukan pada atap sekunder dibanding atap primer.

- Bouwplan VII merupakan bouwplan yang mempunyai tipe atap terbanyak, sedangkan tipe atap tersedikit berada di bouwplan III. Fenomena terakhir bisa dimengerti karena populasi dan sampelnya hanya tunggal.

- Bentuk atap di wilayah studi dipengaruhi oleh tradisi yang berasal dari lokal vernakular, Tionghoa dan Eropa.

- Keberadaan tradisi arsitektur Tionghoa di bouwplan VIII tidak bisa dilepaskan dari karakteristik fungsi dan pemilik bangunan yang didominasi oleh masyarakat Tionghoa.

- Bouwplan VIII merupakan satu-satunya bouwplan yang mendapat pengaruh tradisi arsitektural Tionghoa.

\subsubsection{Bukaan}

Secara garis besar hanya ada dua tipe dasar bukaan, bukaan berraut persegi dan lingkaran. Bukaan tipe lingkaran tidak ada variannya, sedangkan bukaan persegi memiliki enam varian, mulai dari persegi murni hingga kombinasi persegi dengan raut mansard. Tipe bukaan selengkapnya tersaji dalam matriks berikut ini.

Tabel 3. Tipe Bukaan

\begin{tabular}{|c|c|c|}
\hline Tipe Bukaan & Bouwplan & Pengaruh \\
\hline Murni & I, II, III, IV, V, VI, VII, VIII & Lokal vernakular, Eropa \\
\hline Persegi + lengkung segmental & I, VIII & \multirow{3}{*}{ Eropa } \\
\hline Persegi + lengkung meruncing & I & \\
\hline $\begin{array}{l}\text { Persegi + lengkung semi } \\
\text { sirkular }\end{array}$ & I, II. VII. VIII & \\
\hline
\end{tabular}




\begin{tabular}{|l|l|l|l|l|}
\hline \multicolumn{2}{|c|}{ Tipe Bukaan } & Bouwplan & Pengaruh \\
\hline & Persegi + segitiga sama kaki & & \\
\cline { 2 - 5 } & Persegi + mansard & III & \\
\hline Lingkaran & Murni & Eropa & \\
\hline
\end{tabular}

Dari tabel di atas, dapat diketahui beberapa hal berikut ini:

- Dominasi raut persegi murni di semua bouwplan. Ini bisa dimengerti karena raut tersebut merupakan raut yang paling mudah dibuat dan terekonomis.

- Variasi raut persegi terbanyak adalah kombinasi persegi dengan lengkung semisirkular.

- Raut persegi dengan lengkung semi sirkular merupakan raut bukaan yang berasal dari tradisi arsitektural Eropa yang terbanyak dipakai, disusul dengan raut lingkaran, persegi dengan lengkung segmental.

- Bouwplan IV dan V merupakan dua bouwplan yang semuanya menggunakan raut bukaan persegi murni. Yang menarik adalah bahwa meski bouwplan V ditujukan bagi masyarakat Eropa (yang berkonotasi masyarakat mampu), tetapi ditinjau dari pemakaian bukaan, tidak ada upaya penggunaan bukaan selain bukaan berraut persegi murni.

\section{Kesimpulan}

Dari analisis yang sudah dilakukan pada bagian sebelumnya, bisa dinyatakan beberapa temuan sebagai berikut:

- Pengaruh tradisionalisme dalam arsitektur kolonial Belanda di Kota Malang memang benar-benar ada.

- Pengaruh tersebut bisa ditemui dalam hal desain bentuk atap dan desain raut bukaan.

- Desain bentuk atap dan raut bukaan dipengaruhi oleh tradisi lokal vernakular, Tionghoa dan Eropa.

- Terapan tradisi arsitektur lokal vernakular pada atap dikenali dari pemakaian atap pelana, limas segi empat.

- Terapan tradisi arsitektur Tionghoa ditemukan dengan adanya penggunaan atap lonceng lengkung.

- Terapan tradisi arsitektur Eropa dijumpai pada penggunaan atap datar, mansard, lonceng, limas segi delapan, kerucut, serta pemakaian elemen menara, dormer dan cerobong asap.

- Ada kaitan antara pemakai bangunan (di awal perencanaan bouwplan) dengan asal terapan tradisi arsitekturalnya.

- Ada korelasi positif antara tingkat ekonomi pemakai bangunan dengan keragaman bentuk atap. Semakin tinggi tingkat ekonomi dan sosial konsumen atau pengguna bangunan di suatu bouwplan maka semakin beragam tipe atau variasi bentuk atapnya.

- Terapan tradisi arsitektur lokal vernakular pada bukaan dikenali dari pemakaian raut persegi. 
- Terapan tradisi arsitektur Eropa dijumpai pada penggunaan raut bukaan kombinasi antara persegi dengan lengkung (segmental, meruncing dan semi sirkular), mansard, segitiga sama kaki dan lingkaran.

Kurang ada kaitan antara keragaman tipe/variasi atap dengan tipe/variasi raut bukaan di suatu bouwplan.

\section{Daftar Pustaka}

Akihary, H. (1990). Architectuur \& Stedebouw in Indonesië 1870/1970. Zutphen: De Walburg Pers. . (1996). Ir. F.J.L. Ghijsels: Architect in Indonesia (1910-1929). Utrecht: Seram Press.

Barbieri, S. Umberto dan Duin, Leen van (eds.). (2003). A Hundred Years of Dutch Architecture 1901-2000: Trend Highlights. Amsterdam: Sun Publisher.

Dikken, Judy den. (2002). Liem Bwan Tjie (1891-1966): Westerse Vernieuwing en Oosterse Traditie. Rotterdam: BONAS.

Dullemen, C.J. van. (2010). Tropical Modernity: Life and Work of C.P. Wolff Schoemaker. Amsterdam: Sun Publisher.

Handinoto dan Soehargo, Paulus H. (1996). Perkembangan Kota dan Arsitektur Kolonial Belanda di Malang. Surabaya: Lembaga Penelitian dan Pengabdian kepada Masyarakat, Universitas Kristen Petra.

Jencks, Charles. (1977).Language of Post-Modern Architecture. New York: Rizzoli.

Jessup, Helen Ibbitson. 1988. Netherlands Architecture in Indonesia 1900-1942. disertasi doktor. London: Courtauld Institute of Art.

Leerdam, Ben F. van. (1988). Henri Maclaine Pont: Architect tussen Twee Werelden. Delft: DelftseUniversitaire Press.

Liempt, F.J.M. van. (1939). Stadsgemeente Malang 1914-1939. Soerabaia: G. Kolff \& Co.

Moehadjir, Noeng. (1989). Metodologi Penelitian Kualitatif: Telaahan Positivistik, Rasionalistik dan Phenomenologik. Yogyakarta: Rake Sarasin.

Rahaju B.U.K., Sri. (2010). “Arsitektur Tradisional di Indonesia: Gagasan dan Artiefak Budaya”, Hanan, Himasari. Sejarah, Teori dan Kritik Arsitektur. Bandung: Kelompok Keahlian Sejarah, Teori dan Kritik Arsitektur SAPPK ITB.

Santoso, Joko Triwinarto. (2010). A Study of Architect Cosman Citroen (1881-1935) and his Works in Surabaya, disertasi doktor. Leiden: Universiteit Leiden.

Schaik, A. van. (1996). Malang: Beeld van een Stad. Purmerend: Asia Maior.

Segaar-Höweler, Dorothee C. (1998). J.M. Groenewegen (1888-1980): een Hagenaar als Indonesisch Architect. Rotterdam: BONAS.

dan Boersma, Tjeerd. (2000). A.F. Aalbers (1897-1961): Ondogmatisch Modernist in een Koloniale Samenleving. Rotterdam: BONAS.

Soekiman, Djoko. (2000). Kebudayaan Indis dan Gaya Hidup Masyarakat Pendukungnya di Jawa. Yogyakarta: Yayasan Bentang Budaya.

. (2007) ."Kebudayaan Indis dan Gaya Hidup Masyarakat Pendukungnya di Jawa (Abad XVIII sampai medio Abad XX)", Margana, Sri dan Priyatmoko, Heri (eds.). Kolonialisme, Kebudayaan dan Warisan Sejarah. Yogyakarta: Jurusan Sejarah Fakultas Ilmu Budaya Universitas Gadjah Mada.

Sudradjat, Iwan. (1991). A Study of Indonesian Architectural History. disertasi doktor. Sydney: University of Sydney.

Sugiyono. (2006). Metode Penelitian Kuantitatif, Kualitatif dan R \& D. Bandung: Alfabeta.

Sumalyo, Yulianto. (1993). Arsitektur Kolonial Belanda di Indonesia. Yogyakarta: Gadjah Mada University Press. 
Vletter, Martien de. (2007). "Tradition and Modernity in the Netherlands East Indies", Nas, Peter J.M. (ed). The Past in the Present: Architecture in Indonesia. Leiden: KITLV Press.

Vries, Gerrit de, dan Segaar-Höweler, Dorothee C. (2009).Henri Maclaine Pont: Architect, Constructeur, Archeoloog. Rotterdam: BONAS.

Wuisman, Jan J.M. (2007). "The Past in the Present: the Place and Role of Indonesian Vernacular Architectural Traditions and Building Styles of the Past in the Present", Nas, Peter J.M. (ed). The Past in the Present: Architecture in Indonesia. Leiden: KITLV Press. 